\title{
Pengaruh Panjang Serat Terhadap Kekuatan Tarik dan Kekuatan Impact Greencomposite Serat Kulit Buah Pinang dengan Matriks Getah Pinus
}

\author{
CIPK Kencanawati $^{1{ }^{\star}}$, NPG Suardana ${ }^{1)}$, I Ketut Gede Sugita ${ }^{1)}$, \\ I W Budiasa Suyasa ${ }^{2)}$ \\ 1) Jurusan Teknik Mesin Universitas Udayana, Kampus Bukit Jimbaran Bali \\ 2) Jurusan Kimia FMIPA Universitas Udayana, Kampus Bukit Jimbaran Bali \\ Naskah diterima 5/03/2019; direvisi 18/04/2019; disetujui 25/04/2019 \\ doi: https://doi.org/10.24843/JEM.2019.v12.i01.p06
}

\begin{abstract}
Abstrak
Penelitian pemanfaatan bahan-bahan alam dalam bidang rekayasa komposit sudah menjadi sesuatu yang penting, mengingat semakin terbatasnya sumberdaya yang ada serta permasalahan lingkungan yang dapat terjadi dari penggunaan bahan-bahan non alami. Penelitian greencomposite getah pinus yang diperkuat dengan serat kulit buah pinang ini bertujuan mengetahui karakteristik mekanik berupa kekuatan tarik dan kekuatan Impact dengan memvariasikan panjang serat kulit buah pinang yaitu serbuk (5 mesh), $10 \mathrm{~mm}, 20 \mathrm{~mm}$, dan $30 \mathrm{~mm}$ dengan fraksi volume $85 \%$ matrik getah pinus 15\% serat kulit buah pinang. Dari hasil pengujian didapat harga kekuatan tarik tertinggi dimiliki oleh komposit dengan panjang serat $30 \mathrm{~mm}$ yaitu $13,677 \mathrm{MPa}$, dengan elengation 8,998\%, kekuatan Impact tertinggi dimiliki oleh greencomposite dengan panjang serat $30 \mathrm{~mm}$ yaitu 0,0097 $\mathrm{j} / \mathrm{mm}^{2}$.
\end{abstract}

Kata Kunci : serat kulit buah pinang, kekuatan tarik, kekuatan Impact

\begin{abstract}
Research on the utilization of natural materials in the field of composite engineering has become something important, given the limited resources available and environmental problems that can occur from the use of non-natural materials. The research of greencomposite pine resin which is reinforced with areca husk fibers purposed to determine the mechanical characteristics of tensile strength and Impact strength by varying the length of areca husk fibers are powder ( $5 \mathrm{mesh}), 10 \mathrm{~mm}, 20 \mathrm{~mm}$ and 30 $\mathrm{mm}$ with a volume fraction of $85 \%$ pine resin and $15 \%$ areca husk fibers. From the test results obtained the highest tensile strength is owned by a composite with the fibers length of $30 \mathrm{~mm}, 13.677 \mathrm{MPa}$ and elangation of $8.998 \%$, the highest Impact strength is owned by a greencomposite with a fibers length of $30 \mathrm{~mm}$ which is $0,0097 \mathrm{j} / \mathrm{mm}^{2}$.
\end{abstract}

Keywords: areca husk fibers, tensile strength, Impact strength

\section{Pendahuluan}

Perkembangan pemanfaatan bahan-bahan alami dalam bidang rekayasa material komposit saat ini mengalami perkembangan yang sangat pesat, seiring dengan semakin berkurangnya sumberdaya bahan non alami dan disamping itu bahaya yang dapat ditimbulkan dengan penggunaan bahan sintetis.

Komposit yang ramah lingkungan yang dikenal dengan istilah greencomposite adalah material komposit yang merupakan gabungan dari resin alami dengan penguat yang berasal dari alam. Keunggulan penggunaan material greencomposites yaitu sumberdaya yang terbarukan, bisa didegradasi oleh alam, dan Hidrofobik (tak suka air) tetapi greencomposites juga memiliki beberapa kelemahan wetability yang rendah, ketidakcocokan dengan beberapa matriks polimer, dan titik leleh rendah. Namun demikian kelemahan tersebut dapat diatasi dengan beberapa perlakukan kimia (Suardana et al., 2010)

Material komposit terdiri dari dua unsur yang berbeda, yaitu matrik sebagai pengisi atau bahan pengikat serat-serat yang akan menahan fasa penguat dan meneruskan beban. Bahan penguat (reinforce) merupakan fasa kedua dan diskontinu yang dimasukkan ke dalam matrik. Penggunaan penguat sendiri yang utama adalah untuk menentukan karakteristik bahan komposit, seperti : kekakuan, kekuatan serta sifat-sifat mekanik lainnya, karena penguat digunakan untuk menahan sebagian besar gaya yang bekerja pada bahan komposit. Matrik sendiri mempunyai fungsi melindungi dan mengikat filler agar dapat bekerja dengan baik terhadap gaya-gaya yang terjadi. Bahan filler digunakan bahan yang kuat, kaku dan getas, sedangkan bahan matrik dipilih bahan-bahan yang liat, lunak dan tahan terhadap perlakuan kimia (John and Anandjiwala, 2008),

Pemanfaatan getah pinus sebagai matriks alam berdasarkan pada karakteristiknya yang memiliki daya rekat yang cukup tinggi dan hydrophobic sehingga sesuai dipergunakan dalam rekayasa bahan komposit. Getah pinus dihasilkan dari penyadapan batang pohon pinus, getah ini bila dipanaskan, maka kandungan terpentin dalam getah akan menguap sehingga akan tersisa ampas getah 
yang disebut dengan Gondorukem. Penelitian yang dilakukan (C. Kencanawati et al., 2017) getah pinus memiliki density sebesar $1,1 \mathrm{gr} / \mathrm{cm}^{3}$, dan softening point pada temperatur antara 65 sampai dengan $75^{\circ} \mathrm{C}$. Dalam penelitian pui08 penggunaan gondorukem sebagai perekat menunjukkan nilai bahwa nilai fractal colophony sebesar 1,3319 yang berarti bahwa colophony memiliki tingkat keberaturan butir/agregat yang kurang beraturan sehingga memudahkan zat/unsur lain untuk terabsorpsi ke struktur butirnya atau dengan kata lain memiliki daya rekat yang cukup baik. Berdasarkan karakteristik sifat gondorukem tersebut maka dimungkinkan penggunaannya sebagai matriks dalam komposit, mengingat potensi pengembangkan komposit alam sangat tinggi.

Penggunaan serat kulit buah pinang yang selama ini pemanfaatannya masih terbatas. Pohon pinang dalam perdagangan dunia dikenal sebagai Areca catechu $L$ merupakan salah satu tumbuhan palma (Toldy et al., 2005). Selama ini bagian pinang yang banyak dimanfaatkan selama ini adalah bagian daun, batang dan biji. Sementara itu bagian sabut pinang tersebut terbuang dengan percuma tanpa digunakan atau dimanfaatkan lebih lanjut. Mengingat pemanfaatan serat pinang secara langsung sangat sedikit, maka perlu ada inovasi untuk pemanfaatan serat pinang seperti pembuatan komposit alam. Serat pinang merupakan salah satu material fibre alternatif dalam pembuatan komposit secara ilmiah pemanfaatannya masih dikembangkan karena serat pinang selain mudah didapat, murah, dapat mengurangi polusi lingkungan sehingga komposit ini mampu mengatasi permasalahan lingkungan, serta tidak membahayakan kesehatan(sampa14, dhan15,. Kekuatan tarik serat tunggal dari serat kulit buah pinang sebesar $148 \mathrm{MPa}$ dan Modulus Young sebesar 2.327 MPa. (C. I. P. K. Kencanawati et al., 2017). Sehingga pengembangan serat pinang sebagai material komposit ini sangat dimaklumi mengingat dari segi ketersediaan bahan baku serat alam indonesia yang memiliki bahan baku yang cukup melimpah. Adapun komposit dengan penguat serat alam mempunyai keuntungan antara lain kekuatan spesifik dan modulusnya yang tinggi, densitas rendah, harga rendah, melimpah di banyak negara, emisi polusi yang lebih rendah dan dapat di daur ulang.

Dari penelitian ini diharapkan akan mendapatkan jenis material green komposit yang benar-benar ramah lingkungan serta memiliki sifat mekanik yang baik, sehingga ke depannya nanti semakin berkurang penggunaan bahan-bahan yang tidak ramah lingkungan. Selain itu semakin berkembangnya komposit tidak hanya menggunakan serat alam tetapi matriksnya juga dari bahan alam yang selama ini keberadaannya hanya sebagai limbah atau bahan yang kurang termanfaatkan saja.

\section{Metode Penelitian}

\subsection{Bahan}

Serat kulit buah pinang diperoleh dari perkebunan pinang lokal di Desa Payangan Kabupaten Gianyar, dan getah pinus diperoleh dari penyadapan pohon pinus jenis pinus merkusii yang tumbuh dikawasan KPH Bali Timur.

\subsection{Persiapan serat kulit buah pinang}

Buah pinang direndam dalam air pada temperatur kamar selama 1 hari untuk melonggarkan serat. Serat dipisahkan secara manual dari bagian bijinya dan dicuci bersih dengan aquades beberapa kali untuk menghilangkan kotoran, sebelum pengeringan dalam oven pada $70^{\circ} \mathrm{C}$ selama 24 jam.

\subsection{Persiapan getah pinus}

Getah pinus diperoleh dengan metode penyadapan sistem bor, hal ini dilakukan agar tidak merusak batang pohon secara makro. Selanjutnya getah pinus dipanaskan pada temperatur $170^{\circ} \mathrm{C}$, selama \pm 15 menit hingga mencair dan mulai mengalami perubahan volume hal ini menandakan gas terpentine terkandung dalam getah pinus mulai menguap.

\subsection{Pembuatan greencomposite serat kulit buah pinang dan getah pinus.}

Pembuatan composite dengan memvariasikan ukuran serbuk penguatnya yaitu serat kulit buah pinang yang berbentuk serbuk ( $<5$ mesh), $10 \mathrm{~mm}, 20$ $\mathrm{mm}$ dan $30 \mathrm{~mm}$ dengan perbandingan serat dan matriksnya sebesar $85 \%$ : $15 \%$. Selanjutnya campuran tersebut dicetak pada cetakan spesimen uji tarik ASTM D638 dan spesimen uji Impact sesuai ASTM D256.

\section{Hasil dan Pembahasan}

\subsection{Kekuatan Tarik Greencomposite}

Pengujian tarik dilakukan untuk mengetahui besarnya kekuatan tarik dari bahan greencomposite. Pada penelitian ini, menggunakan dimensi spesimen uji menurut ASTM D638-02a dengan dimensi cetakan sebagai berikut :

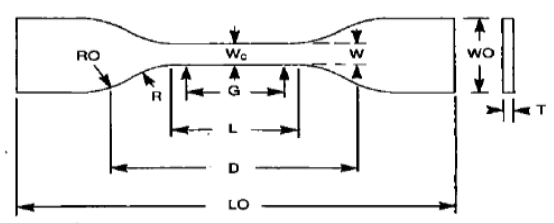

Gambar 1. Geometri Spesimen Uji Tarik ASTM D638 Hasil pengujian kekuatan tarik dari greencomposite serat kulit buah pinang dan getah pinus, seperti tersaji pada tabel 1. 
Tabel 1. Kekuatan tarik greencomposite

\begin{tabular}{|l|c|c|c|}
\hline $\begin{array}{c}\text { Ukuran serat } \\
\text { greencomposite }\end{array}$ & $\begin{array}{c}\text { Tensile } \\
\text { strength } \\
(\mathrm{MPa})\end{array}$ & $\begin{array}{c}\text { Young's } \\
\text { Modulus } \\
(\mathrm{Gpa})\end{array}$ & $\begin{array}{c}\text { Elengation } \\
(\%)\end{array}$ \\
\hline Serbuk - 1 & 1,455 & 0,523 & 0,925 \\
\hline Serbuk - 2 & 1,322 & 0,435 & 1,220 \\
\hline Serbuk - 3 & 1,266 & 0,571 & 0,954 \\
\hline Rata-rata & $\mathbf{1 , 3 4 8}$ & $\mathbf{0 , 5 1 0}$ & $\mathbf{1 , 0 3 3}$ \\
\hline $10 \mathrm{~mm}-1$ & 8,424 & 0,588 & 5,345 \\
\hline $10 \mathrm{~mm}-2$ & 8,100 & 0,589 & 5,122 \\
\hline $10 \mathrm{~mm}-3$ & 8,522 & 0,559 & 4,998 \\
\hline Rata-rata & $\mathbf{8 , 3 4 9}$ & $\mathbf{0 , 5 7 9}$ & $\mathbf{5 , 1 5 5}$ \\
\hline $20 \mathrm{~mm}-1$ & 10,392 & 0,635 & 7,568 \\
\hline $20 \mathrm{~mm}-2$ & 10,449 & 0,598 & 7,338 \\
\hline $20 \mathrm{~mm}-3$ & 11,323 & 0,621 & 7,011 \\
\hline Rata-rata & $\mathbf{1 0 , 7 2 1}$ & $\mathbf{0 , 6 1 8}$ & $\mathbf{7 , 3 0 6}$ \\
\hline $30 \mathrm{~mm}-1$ & 13,367 & 0,672 & 8,753 \\
\hline $30 \mathrm{~mm}-2$ & 14,003 & 0,704 & 8,99 \\
\hline $30 \mathrm{~mm}-3$ & 13,66 & 0,732 & 9,252 \\
\hline Rata-rata & $\mathbf{1 3 , 6 7 7}$ & $\mathbf{0 , 7 0 3}$ & $\mathbf{8 , 9 9 8}$ \\
\hline
\end{tabular}

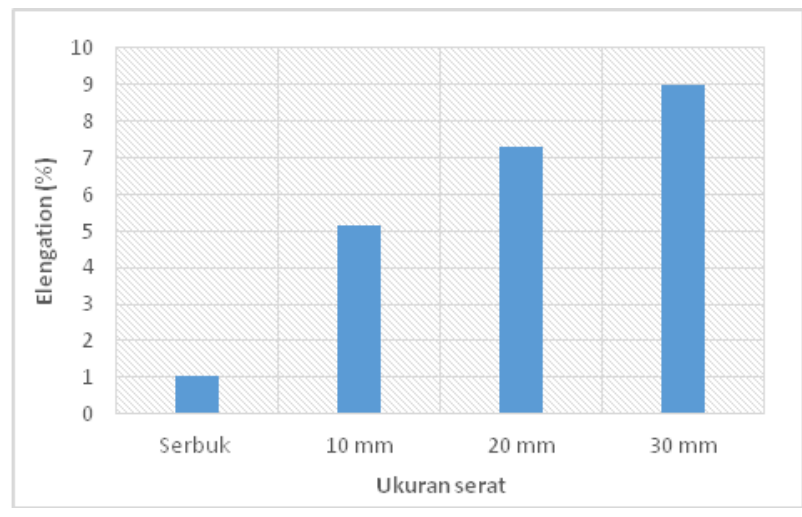

Gambar 2. Kurva kekuatan tarik greencomposite

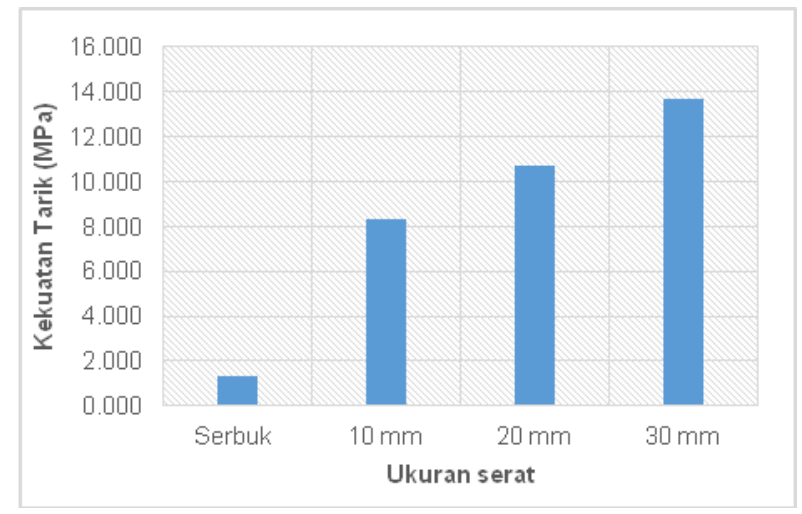

Gambar 3. Kurva elengation greencomposite

Gambar 2 dan 3 menunjukkan bahwa kurva tegangan-regangan greencomposite dengan berbagai variasi ukuran serat sesuai dengan standar ASTM D 638, serat yang berbentuk serbuk $(<5$ mesh), $10 \mathrm{~mm}, 20 \mathrm{~mm}$ dan $30 \mathrm{~mm}$ dengan perbandingan serat dan matriksnya sebesar $85 \%$ : $15 \%$. Kurva tegangan regangan menunjukkan bahwa serat dengan panjang $30 \mathrm{~mm}$ merupakan ukuran serat yang paling baik kekuatan tariknya yaitu sebesar 13, $677 \mathrm{MPa}$, demikian juga regangan yang dihasilkan yaitu sebesar $8,998 \%$. Dari pengujian kekuatan tarik yang dilakukan terlihat bahwa semakin meningkat kekuatan tarik dan elengation material dengan semakin panjangnya ukuran seratnya. Sedangkan kekuatan tarik dan elengation yang terkecil pada greencomposite dengan ukuran serat $>5$ mesh yaitu sebesar $1,348 \mathrm{MPa}$ dan $1,033 \%$, baik kekuatan tarik dan elengationnya sangat kecil hal ini dikarenakan serat yang terkandung dalam material tidak cukup mampu untuk menahan tegangan yang diberikan kepada material uji tersebut.

\subsection{Kekuatan Impact Greencomposite}

Pada uji Impact dengan metode charpy, peneliti mengukur energi yang diserap untuk mematahkan benda uji. Setelah benda uji patah, bandul berayun kembali. Semakin besar energi yang diserap maka semakin rendah ayunan kembali dari bandul. Energi patahan yang diserap biasanya dinyatakan dalam satuan joule. Pada penetilitan ini menggunakan spesimen uji berdasarkan ASTM D256 dengan dimensi sebagai berikut:

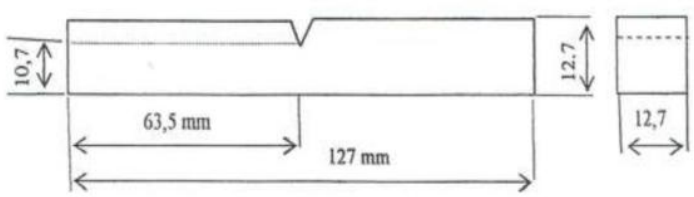

\section{Gambar 4. Spesimen Uji Impact ASTM D256}

Hasil pengujian kekuatan Impact dari greencomposite serat kulit buah pinang dan getah pinus, seperti tersaji pada tabel 2. Untuk hasil pengujian impact rata-rata yang tertinggi adalah greencomposite serat dengan panjang $30 \mathrm{~mm}$ yaitu sebesar $0,97 \times 10^{-3} \mathrm{~J} / \mathrm{mm}^{2}$ sedangkan yang terendah adalah greencomposite dengan ukuran serat $<5$ mesh dengan kekuatan Impact rata-rata sebesar $0,75 \times 10^{-3} \mathrm{~J} / \mathrm{mm}^{2}$.

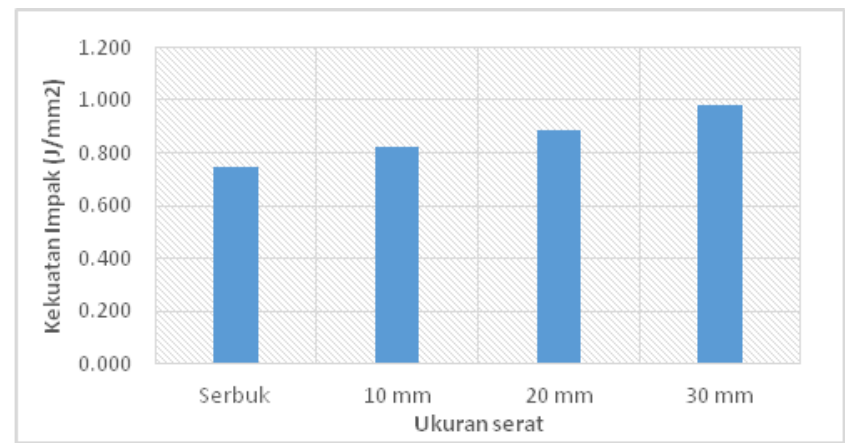

Gambar 5. Kurva kekuatan Impact greencomposite 
Tabel 1. Kekuatan Impact greencomposite

\begin{tabular}{|l|c|c|c|}
\hline $\begin{array}{c}\text { Ukuran serat } \\
\text { greencomposit } \\
e\end{array}$ & $\begin{array}{c}\mathrm{A} \\
\left(\mathrm{mm}^{2}\right)\end{array}$ & $\begin{array}{c}\Delta \mathrm{E} \\
(\mathrm{Nm})\end{array}$ & $\begin{array}{c}\mathbf{I}_{\mathbf{s}} \\
\left(\mathrm{J} / \mathrm{mm}^{2}\right) \\
\left(\times 10^{-3}\right)\end{array}$ \\
\hline Serbuk - 1 & 117 & 0,0766 & 0,65 \\
\hline Serbuk - 2 & 110 & 0,0858 & 0,78 \\
\hline Serbuk - 3 & 109 & 0,0877 & 0,80 \\
\hline Rata-rata & $\mathbf{1 1 2}$ & $\mathbf{0 , 0 8 3 4}$ & $\mathbf{0 , 7 5}$ \\
\hline $10 \mathrm{~mm}-1$ & 106 & 0,0893 & 0,84 \\
\hline $10 \mathrm{~mm}-2$ & 109 & 0,0852 & 0,78 \\
\hline $10 \mathrm{~mm}-3$ & 106 & 0,0892 & 0,84 \\
\hline Rata-rata & $\mathbf{1 0 7}$ & $\mathbf{0 , 0 8 7 9}$ & $\mathbf{0 , 8 2}$ \\
\hline $20 \mathrm{~mm}-1$ & 110 & 0,0983 & 0,89 \\
\hline $20 \mathrm{~mm}-2$ & 113 & 0,0995 & 0,88 \\
\hline $20 \mathrm{~mm}-3$ & 109 & 0,0959 & 0,88 \\
\hline Rata-rata & $\mathbf{1 1 1}$ & $\mathbf{0 , 0 9 7 9}$ & $\mathbf{0 , 8 8}$ \\
\hline 30 mm -1 & 112 & 0,1034 & 0,92 \\
\hline $30 \mathrm{~mm}-2$ & 112 & 0,1110 & 0,99 \\
\hline $30 \mathrm{~mm}-3$ & 110 & 0,1108 & 1,01 \\
\hline Rata-rata & $\mathbf{1 1 1}$ & $\mathbf{0 , 1 0 8 4}$ & $\mathbf{0 , 9 7}$ \\
\hline
\end{tabular}

Perbedaan harga impact rata-rata dari keempat jenis greencomposite disebabkan oleh beberapa hal antara lain adalah kekuatan greencomposite yang kurang merata disetiap tempat dan distribusi serat yang kurang merata sehingga energi yang diserap menjadi lebih kecil. Sedangkan patahan yang terjadi adalah jenis patahan getas.

\section{Simpulan}

Berdasarkan hasil pengujian kekuatan tarik dan kekuatan impact greencmposite serat kulit buah pinang dengan matriks getah pinus maka disimpulkan bahwa :

1. Adanya peningkatan kekuatan tarik dengan semakin panjangnya ukuran serat pada greencomposite, dimana kekuatan tarik tertinggi adalah pada serat dengan panjang $30 \mathrm{~mm}$ sebesar 13,667 $\mathrm{MPa}$, dan elengation sebesar $8,998 \%$.

2. Kekuatan Impact pada greencomposite tidak terjadi peningkatan secara signifikan dengan bervariasinya ukuran serat, dari hasil pengujian impact kekuatan impact tertinggi pada spesimen uji dengan ukuran serat $30 \mathrm{~mm}$ yaitu sebesar $0,0097 \mathrm{~J} / \mathrm{mm}^{2}$.

\section{Ucapan Terima Kasih}

Ucapan terima kasih atau penghargaan bisa disampaikan kepada Fakultas Teknik, dan LPPM Universitas Udayana yang telah membantu pendanaan dalam penelitian ini.

\section{Daftar Pustaka}

[1] John, M. J. and Anandjiwala, R. D. (2008) 'Recent Developments in Chemical Modification and Characterization of Natural Fiber-Reinforced Composites'. doi: 10.1002/pc.

[2] Kencanawati, C. et al. (2017) 'Characterization physical, mechanical, thermal and morphological properties of Colophony', International Journal of Engineering and Emerging Technology, 2(2), pp. 17-19.

[3] Kencanawati, C. I. P. K. et al. (2017) 'A study on biocomposite from local balinese areca catechu I. husk fibers as reinforced material', in IOP Conference Series: Materials Science and Engineering. doi: 10.1088/1757899X/201/1/012002.

[4] Suardana, N. P. G. et al. (2010) 'Mechanical properties and biodegradability of Green composites based on polylactic-acid polymer Mechanical properties and biodegradability of Green composites on polylactic-acid polymer', pp. $1-6$.

[5] Toldy, A. et al. (2005) 'Flame retardancy of biodegradable polymers and biocomposites', 88 , pp. 138-145. doi: 10.1016/j.polymdegradstab.2004.02.023. 